\title{
Developing Drugs For Developing Countries
}

\begin{abstract}
Linking incentives for essential drugs in developing countries with "blockbuster" drugs in the developed world would help both achieve better population health.
\end{abstract}

\section{by David B. Ridley, Henry G. Grabowski, and Jeffrey L. Moe}

ABSTRACT: Infectious and parasitic diseases create enormous health burdens, but because most of the people suffering from these diseases are poor, little is invested in developing treatments. We propose that developers of treatments for neglected diseases receive a "priority review voucher." The voucher could save an average of one year of U.S. Food and Drug Administration (FDA) review and be sold by the developer to the manufacturer of a blockbuster drug. In a well-functioning market, the voucher would speed access to highly valued treatments. Thus, the voucher could benefit consumers in both developing and developed countries at relatively low cost to the taxpayer. [Health Affairs 25, no. 2 (2006): 313-324; 10.1377/hlthaff.25.2.313]

I NFECTIOUS AND PARASITIC DISEASES accounted for more than half of healthy years lost in Africa in 2002, but only 3 percent of healthy years lost in developed countries. ${ }^{1}$ Communicable diseases that disproportionately affect people in developing countries include malaria, leishmaniasis, Chagas disease, tuberculosis, dengue fever, and African trypanosomiasis. Lack of scientific knowledge is not the major barrier to drug development for many of these diseases. Scientists know more about the biology, immunology, and genetics of leishmania and trypanosomes than any other parasites. ${ }^{2}$ Rather, successful compounds often do not enter costly clinical development. ${ }^{3}$ The barrier is a lack of financial incentive. Because most people suffering from these neglected diseases live in low-income countries, there is little financial incentive for private pharmaceutical companies to invest in research and development (R\&D) for new treatments. ${ }^{4}$

We propose a "priority-review voucher" as an incentive to drug companies to develop therapies for neglected diseases. To receive a voucher, a therapy must meet the following criteria: (1) treat neglected diseases such as African trypanosomiasis, Chagas disease, leishmaniasis, or dengue fever; (2) receive approval by the David Ridley (david.ridley@duke.edu) is an assistant professor of the practice of health sector management in the Fuqua School of Business, Duke University, in Durham, North Carolina. Henry Grabowski is a professor of economics in the Department of Economics, Duke University. Jeffrey Moe is an executive-in-residence in the Health Sector Management program, Fuqua School.

HEALTH AFFAIRS Volume 25, Number 2 
U.S. Food and Drug Administration (FDA) or the European Agency for the Evaluation of Medicinal Products; (3) be clinically superior to existing treatments, (4) forgo patent rights; and (5) find at least one manufacturer for the product. ${ }^{5}$ The awarded transferable voucher would entitle the bearer to priority FDA review for another drug (or possibly multiple drugs) and orphan drug tax credits.

The FDA awards priority status to drugs according to their perceived novelty. In the 1990s, fourteen of twenty-nine "blockbuster drugs" (those with sales of $\$ 1$ billion in their fifth year on the market) were classified as priority (Exhibit 1). Drugs that did not receive priority review but went on to be market leaders include Zocor (simvastatin) for cholesterol, Norvasc (amlodipine) for hypertension,

EXHIBIT 1

Priority Ratings For Drugs Launched In The 1990s That Achieved Sales Of \$1 Billion By The Fifth Year Following Launch

\begin{tabular}{lll}
\hline Trade name & Approval date & Review classification \\
\hline Pravachol & $10 / 1991$ & Standard \\
Biaxin & $10 / 1991$ & Priority \\
Zocor & $12 / 1992$ & Standard \\
Zoloft & $12 / 1991$ & Standard \\
\hline Norvasc & $7 / 1992$ & Standard \\
Taxol & $12 / 1992$ & Priority \\
Paxil & $12 / 1992$ & Standard \\
Imitrex & $12 / 1992$ & Priority \\
Claritin & $4 / 1993$ & Standard \\
\hline Propulsid & $7 / 1993$ & Standard \\
Glucophage & $12 / 1994$ & Priority \\
Cozaar & $4 / 1995$ & Standard \\
Prevacid & $5 / 1995$ & Standard \\
Fosamax & $9 / 1995$ & Priority \\
\hline Allegra & $7 / 1996$ & Standard \\
Zyprexa & $9 / 1996$ & Standard \\
Diovan & $12 / 1996$ & Standard \\
Lipitor & $12 / 1996$ & Priority \\
Seroquel & $9 / 1997$ & Standard \\
\hline Plavix & $11 / 1997$ & Priority \\
Rituxan & $11 / 1997$ & Priority \\
Singulair & $2 / 1998$ & Standard \\
Viagra & $3 / 1998$ & Priority \\
Celexa & $7 / 1998$ & Standard \\
\hline Remicade & $8 / 1998$ & Priority \\
Celebrex & $12 / 1998$ & Priority \\
Avandia & $5 / 1999$ & Priority \\
Vioxx & $5 / 1999$ & Priority \\
Actos & $7 / 1999$ & Priority \\
\hline SouRcE: & & \\
\hline
\end{tabular}

SOURCE: Drug sales data from May issues of MedAd News, various years. Review classifications from FDA data provided by Adrian Gottschalk.

NOTES: The FDA used a three-tier (1-A, 1-B, 1-C) rather than two-tier (priority, standard) review classification prior to October 1992. For drugs approved prior to October 1992, the authors converted 1-A and 1-B to priority and 1-C to standard. 
Cozaar (losartan) for hypertension, and Zyprexa (olanzapine) for schizophrenia. Had priority-review vouchers been available, these drugs could have helped patients sooner and earned higher returns. We estimate that a priority-review voucher would be worth more than $\$ 300$ million for a potential blockbuster drug, because it would shorten the time the FDA takes to analyze data from an average of eighteen months to about six months. ${ }^{6}$

Priority review does not entail lower standards for safety and efficacy. It does, however, require that the FDA have additional resources to analyze data more quickly. The cost to the FDA of changing a drug's status from standard to priority is approximately $\$ 1$ million (our estimate), a cost that could be recovered through a user fee to the voucher holder. With this extra user fee, it should not be necessary for the FDA to slow other drugs in the queue.

A variant of our proposal is to auction the priority-review right to a manufacturer. ${ }^{7}$ The proceeds of the auction could then be paid (as a push or pull mechanism) to the developer of a treatment for a neglected disease. This mechanism would also operate as shown in Exhibit 2, except that there would be no transfers between the manufacturer of the potential blockbuster drug and the developer of the treatment for the neglected disease.

The priority-review voucher provides two benefits: faster access to blockbuster drugs in developed countries, and faster access to cures for infectious diseases in developing countries. There are several reasons to link the benefits. First, the voucher creates a market mechanism that identifies drugs for which priority review would be efficient. Second, the two benefits are more likely to achieve government approval when linked, because they appeal to different constituencies.

In this paper we briefly discuss the diseases that primarily affect people in developing countries. We describe push and pull mechanisms designed to increase funding for R\&D. We then estimate the costs and returns to funding R\&D for neglected diseases using transferable priority review rights at the FDA. We then examine six potential limitations of the voucher and discuss extensions.

\section{EXHIBIT 2}

Priority Prescription Drug Review Voucher Schematic

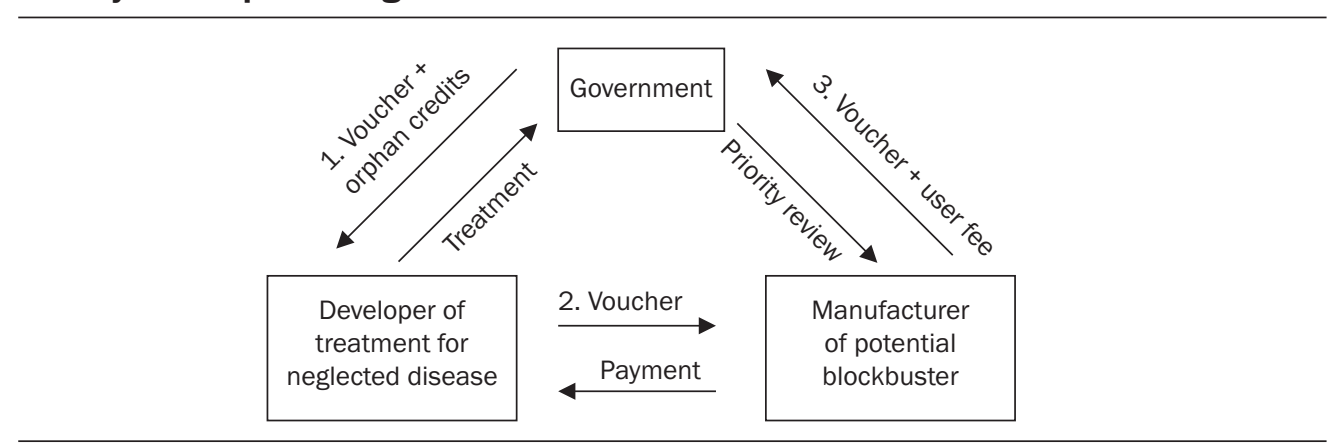

SOURCE: Authors' analysis. 


\section{Diseases Of Developing Countries}

Average spending for health services in low-income countries was just $\$ 23$ per capita in 2001. ${ }^{8}$ Pharmaceutical manufacturers do not expect to earn positive returns on R\&D from the private market for diseases of developing countries. ${ }^{9}$

Three diseases with the greatest burden are HIV/AIDS, malaria, and tuberculosis (Exhibit 3). ${ }^{10}$ Manufacturers do invest in R\&D for HIV/AIDS, because there is a market in both developed and developing countries for these therapies." There is less incentive to invest in R\&D for malaria, because more than 99 percent of disability-adjusted life years (DALYs) lost to malaria are in developing countries. A pipeline of new, more effective vaccines and therapies is needed to treat these diseases, because resistant strains develop and there is a high failure rate for earlystage compounds. Other diseases with a burden of more than one million DALYs - predominantly in developing countries - include tetanus, lymphatic filariasis, trachoma, ascariasis, schistosomiasis, and African trypanosomiasis.

\section{Mechanisms For Stimulating Drug Development}

Mechanisms that subsidize research inputs (those that decrease R\&D costs) are known as "push strategies." Mechanisms that reward research output (those that increase financial returns) are known as "pull strategies." Many of these mechanisms can be regarded as complements rather than substitutes, particularly

\section{EXHIBIT 3}

\section{Distribution Of Global Disease Burden, 2004}

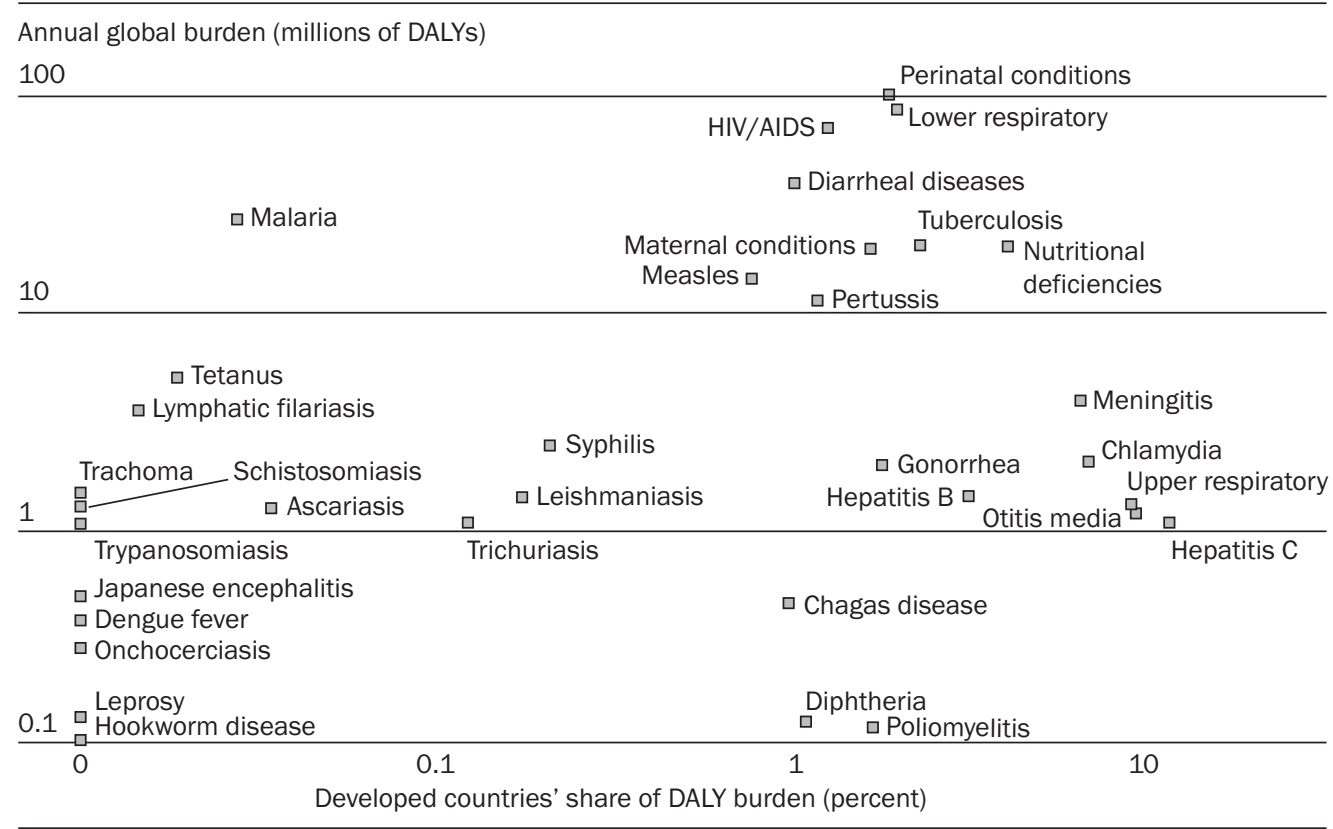

SOURCE: Authors' calculations based on World Health Organization, World Health Report 2004.

NOTES: Data are plotted using a log scale. DALY is disability-adjusted life year. 
pull strategies that do not require funding unless a treatment reaches the market. Furthermore, donors that provide push funding could receive some of the pull reward from the development of a successful product.

The Orphan Drug Act (ODA) of 1983 includes both push and pull mechanisms. First, it provides seven years of marketing exclusivity upon FDA approval. Second, drug makers can qualify for tax credits for up to half of their clinical testing expenses. Third, developers can receive modest FDA grant support to investigate treatments for rare diseases. Fourth, the FDA provides counseling regarding conditions for approval. ${ }^{12}$ The ODA was followed by laws in Japan (1993) and the European Union (2003) that provide similar incentives. ${ }^{13}$

Neglected diseases qualify for orphan drug status because of their low disease prevalence in these countries. A company can qualify for U.S. tax credits for drugs requiring foreign testing when there is an insufficiently large testing population in the United States. As of July 1999, the FDA had granted twenty-five U.S. orphan designations for tropical diseases. ${ }^{14}$

One type of push strategy is the public-private partnership (PPP).${ }^{15} \mathrm{PPPs}$ use philanthropic funding to contract with public-and private-sector entities that develop drug candidates for neglected diseases. ${ }^{16}$ For example, in 2005 the Global Alliance for Vaccines and Immunization (GAVI) received $\$ 750$ million from the Bill and Melinda Gates Foundation and \$290 million from the Norwegian government to increase access to existing vaccines and accelerate R\&D efforts for treatments for neglected diseases. ${ }^{17}$ Push mechanisms reduce the developer's risks and initial costs and can allow the donor greater control over product development. On the other hand, they can suffer from asymmetric information, because the donor has less information than the developer about which projects are the most promising and which costs are appropriate.

Whereas push mechanisms subsidize research inputs, pull mechanisms reward research output. Funders commit to the financing of drug and vaccine purchases for poor countries prior to product development. The Advance Market Commitment Working Group proposed a guaranteed price for a new vaccine for malaria, tuberculosis, or AIDS. Countries would provide a small copayment to ensure that new vaccines meet the market test. They estimate that a market size with present value of sales of $\$ 3$ billion (in 2004 dollars) would be necessary to motivate manufacturers to initiate projects aimed at these diseases. In 2004, Britain's Chancellor of the Exchequer and other donors committed to the purchase of a malaria vaccine if one is developed. ${ }^{18}$

Another pull mechanism is the transferable patent exclusivity right. A developer that licenses a product for a neglected disease would receive additional time on patent for a different product, and this right could be sold to another com pany. ${ }^{19}$ For a risk-averse manufacturer, a voucher for extended patent time might be more valuable than a voucher for priority review, because the manufacturer would be more confident about the value of a product that is already on the mar- 
ket. On the other hand, the voucher for extended patent life would delay access to generic drugs, so the incentive for R\&D for neglected diseases would be paid by consumers of a different drug and their insurers.

\section{Benefits And Costs}

For the priority-review voucher to succeed in improving global welfare, it must satisfy three conditions. First, to create a market for the voucher, the expected net benefit for the manufacturer that purchases the voucher must be non-negative. Second, to induce investment in R\&D for neglected diseases, the expected net benefit for the developer that earns a voucher must be non-negative. Third, the expected net global welfare benefit must be positive. Here we illustrate the costs and benefits of the voucher. Actual figures will depend on the products in question. ${ }^{20}$

- Condition 1: value to the manufacturer. Benefit of priority review over standard review. Manufacturers are willing to spend resources speeding drugs with potentially high market value through the development and approval process. ${ }^{21}$ We estimate that changing a top-decile compound's classification from standard to priority is worth $\$ 322$ million on average to the manufacturer. This estimate is based on changing the review time from 18.4 months to 6.4 months for a top-decile drug with net present value of $\$ 2.92$ billion (in 2004 dollars) and a discount rate of 11 percent. ${ }^{22}$

The voucher is purchased before commercialization, so we assume that the manufacturer is risk-neutral and believes that the product will earn average returns for a top-decile drug. If manufacturers are risk-averse or there is greater uncertainty, or both, priority review will be worth less than $\$ 322$ million. Alternatively, if the manufacturer is risk-neutral and believes that the product will be in the top 5 percent in sales, priority review will be worth more.

We assume that cash flows will be realized one year sooner and that effective patent life and market life will be constant. This is an appropriate assumption for most drugs, given the formula on Hatch-Waxman patent term extensions. ${ }^{23} \mathrm{Be}-$ cause the patent life would be shifted forward by one year, both the pioneer drug and the generic drug would reach the market one year earlier than under standard review. Our estimate of the benefit to the manufacturer is conservative, because the marginal benefit will be even greater in a situation of rapid technological change in which new products displace products with remaining patent life.

Cost of priority review over standard review. We assume that the additional costs to the FDA are passed on to the voucher holder as an additional user fee. We estimate that the cost of priority review is $\$ 2$ million and the cost of standard review is $\$ 1$ million. Hence, the additional cost of moving from standard to priority review is $\$ 1$ million. These estimates are based on an average review cost (user fee plus FDA budget) of $\$ 1.2$ million for all drugs (standard and priority), a cost elasticity of time of -1.2 , and 18.4 months versus 6.4 months for standard versus priority review. ${ }^{24}$ Given that the value of priority review is $\$ 322$ million for a top-decile drug and that the voucher holder would be assessed an additional user fee of $\$ 1$ million, 
the manufacturer of an average top-decile product should be willing to pay up to $\$ 321$ million for a voucher.

Condition 2: value to the developer. To motivate development of a drug for a neglected disease, the selling price of the priority-review voucher(s) plus goodwill must exceed half of the R\&D costs to develop the drug, because the other half of the R\&D costs would be covered by ODA tax credits.

The selling price of the voucher would be approximately $\$ 321$ million. The developer also receives community recognition. Pursuit of goodwill has motivated manufacturers such as Merck to donate ivermectin for river blindness, but additional incentives are need to motivate further R\&D. Furthermore, the voucher provides scientists with an economic justification for pursuing projects that attract them for intellectual and social reasons..$^{25}$

The R\&D program would be eligible for the push incentives included in the ODA, including tax credits for up to half of the clinical testing expenses. If drugs for neglected diseases have the same clinical R\&D costs as the average new drug candidate in the 1990s, capitalized clinical costs would be $\$ 191$ million (in 2000 dollars). ${ }^{26}$ We include the cost of successful and failed trials because all drugs receiving orphan drug status are eligible for tax credits, even those that are not approved. Adjusting using the GDP implicit price deflator, the mean clinical trial cost would be $\$ 504$ million (in 2004 dollars). Thus, a 50 percent tax credit would be $\$ 252$ million.

We believe, however, that the cost of developing a drug for a neglected disease could be much lower than the mean case. First, given the likely acceptance into the FDA's accelerated approval program, orphan drugs might be approved on the basis of a pivotal Phase III clinical trial (or a combined Phase II/III trial). We expect fewer trials, because a drug for a neglected disease would not undergo the extra trials needed for formulary acceptance and reimbursement. ${ }^{27}$ Second, as a result of advances in biotechnology and genomics, there is a greater understanding of the molecular basis of pathogens, and thus higher probability of success and lower R\&D costs for these infectious disease indications. ${ }^{28}$ Third, R\&D efforts associated with bioterrorism should create positive spillover for research for neglected diseases. Fourth, research started for other indications can sometimes yield information for the treatment of neglected diseases.

If one voucher is not sufficient to generate research on neglected diseases, then multiple vouchers could be awarded. For example, two vouchers for two blockbuster drugs could be awarded for every one treatment for a neglected disease.

- Condition 3: social welfare. The social welfare gains to patients (both consumers of the drug for the neglected disease and consumers with earlier access to potential blockbuster drugs) plus the net gains to manufacturers (of both the drug for the neglected disease and the potential blockbuster drug) minus the cost to the government of FDA review and orphan drug status should be positive.

Producer surplus. Assuming that expected net economic returns to the developer 
are zero (that is, the value of the vouchers will equal R\&D costs in long-term equilibrium) provides a lower bound on the social value of the priority-review voucher. In fact, producer surplus will be positive if the value of priority review for a potential blockbuster drug exceeds the net R\&D costs of orphan drug credits for the developer of a drug for a neglected disease.

Consumer surplus from a drug for a neglected disease. The consumer surplus from a drug or vaccine for a neglected disease will depend on the quality of the product, how many people can be treated with it, and the value that society places on human life. As illustrated in Exhibit 3, forty-six million DALYs are lost each year to malaria. A common cost-effectiveness threshold for health interventions in the poorest countries is $\$ 100$ per DALY.$^{29}$ For comparison, health interventions are considered cost-effective in the United States at up to 500-1,000 times this amount. ${ }^{30}$ Thus, the burden is at least $\$ 4.6$ billion per year. A product would be worth $\$ 1$ billion if it could alleviate 22 percent of the burden of malaria for just one year. (Of course, the benefits would extend beyond one year.) Other parasitic and infectious diseases have smaller burdens than malaria, but treatments could be worth $\$ 1$ billion in net present value, given that benefits extend over time. As we demonstrate below, although the benefits to people in developing countries could be enormous, they need not be to justify the priority-review voucher, because of the benefits of faster review for people in developed countries.

Consumer surplus from faster access to a potential blockbuster drug. U.S. consumers will benefit from faster access to new drugs. The manufacturer's price does not extract the entire consumer surplus. Consumer surplus is approximately equal to half of the manufacturer's surplus, so if the producer surplus from faster review (gross of $\mathrm{R} \& \mathrm{D}$ costs) is $\$ 322$ million, then the consumer surplus would be $\$ 161$ million. ${ }^{31}$ This does not include the additional consumer benefit of earlier access to generic drugs resulting from shifting patent life forward by one year.

Government costs. By motivating a manufacturer to create a new treatment for neglected diseases, the U.S. government will bear the additional costs of drug review and orphan drug status. We assume that the FDA will deem the treatment worthy of priority review on its own merits (in addition to giving the developer a priorityreview voucher), at a cost of $\$ 2$ million. We expect that the orphan drug tax credit would cost taxpayers less than $\$ 252$ million, although the amount will be lower if developers can use efficiencies and spillovers from other projects.

Global welfare. We assume that one voucher per drug for a neglected disease is a sufficient incentive, that expected producer surplus equals zero (that is, manufacturers earn normal profits), and that consumer surplus for blockbuster drugs is approximately half of producer surplus. Thus, global welfare equals the consumer surplus from the treatment for a neglected disease plus half of the producer surplus from faster review (approximately $\$ 161$ million) minus the cost of orphan drug tax credits (approximately $\$ 252$ million) and other push mechanisms minus the cost of priority review for the drug for a neglected disease (approximately $\$ 2$ 
million). If the social value of a treatment for a neglected disease is worth at least $\$ 100$ million in net present value, the priority-review voucher would improve global welfare. In fact, we believe that the social value of treatments for neglected diseases could be in the billions of dollars.

\section{Study Limitations}

First, a voucher worth $\$ 321$ million plus orphan drug tax credits of $\$ 252$ million is considerably smaller than the $\$ 3$ billion advance-purchase commitment (APC). The difference exists, in part, because the priority-review voucher uses after-tax profits (sales net of production and distribution costs), whereas the APC estimate is based on pretax sales revenues, gross of any costs. Another difference is that the APC covers the costs of R\&D, manufacturing, distribution, and introduction. For the APC there is an explicit incentive for the developer to ensure consumer access. Nevertheless, a primary difference between the proposals is the generosity of the prize, so the voucher might encourage developers to salvage existing projects that were initiated for other diseases. With a lower cost to the sponsor (for example, taxpayers), the priority-review voucher could be applied to more neglected diseases and still meet a given cost-benefit criterion. Thus, the APC might be available for diseases for which there are sizable donor resources (such as malaria, tuberculosis, or HIV/AIDS), while the priority-review voucher could be applied to a wider class of neglected diseases. If the goal were more development, then more vouchers could be awarded per product discovered.

Second, the incentive mechanism has little value if treatments are developed that do not reach patients. The developer should work with global and local stakeholders prior to FDA approval to ensure that the product will be used. The developer must ensure that someone manufactures the drug, perhaps through technology transfer to a developing country. ${ }^{32}$ Additional charitable efforts might be necessary to support access. Third, developers might fear that the government will not award a voucher as promised. Fortunately, the government is likely to keep its promise since the program is low cost. As is the case for other pull mechanisms, however, it is important to write enforceable contracts. ${ }^{33}$

Fourth, poor people might prefer cash over medicine. We believe that many donors would prefer to give medicine because health is viewed as meritorious, whereas cash can be siphoned by corrupt intermediaries. ${ }^{34}$ Furthermore, medicines have spillover effects and may be international public goods. ${ }^{35}$ Fifth, a voucher might speed the approval of a product with high potential sales but limited clinical benefits. Given FDA approval, we assume that the product has clinical benefits, but if these are small (and yet expected sales are high), then U.S. benefits will be smaller.

Sixth, drugs given priority review might be less safe than those following a standard review time. Priority review, however, does not entail lower standards for safety and efficacy; it requires additional resources. According to FDA data, 
shortening review times does not increase the withdrawal rate. From 1971 to 1993 the withdrawal rate was approximately 2.7 percent; from 1994 to 2004, when review times were dramatically lower, it was 2.3 percent. ${ }^{36}$ On the other hand, Mary Olson found that drugs with faster review times are subject to more adverse drug reactions. ${ }^{37}$ However, Olson's data were limited by a short time period (1990-1995) and limited information on drug usage. A 2005 Tufts study found no correlation between review times and withdrawal rates across therapeutic classes. ${ }^{38}$ The voucher's political viability might be increased by a revamped system of postapproval surveillance, now under review by the FDA and Institute of Medicine. ${ }^{39}$

\section{Concluding Comments}

We propose a novel pull mechanism in which a voucher is awarded for creating and licensing a drug that treats neglected diseases in the developing world. The transferable voucher would give the bearer priority-review status at the FDA for another drug. If the voucher speeds FDA approval by a year, it could increase the present value of sales of a blockbuster drug by more than $\$ 300$ million. The developer also would be eligible for orphan drug tax credits. In a well-functioning voucher market, drugs that consumers and payers value more would reach the market sooner. We estimate that the additional cost of faster FDA review would be $\$ 1$ million and could be passed on to the manufacturer. The cost to the government would be the additional cost associated with any drug for a neglected disease (that is, orphan drug tax credits).

The concept of a priority-review voucher could also be applied to diseases associated with bioterrorism. A bill introduced in the U.S. Senate in 2005 proposes that the developer of a drug that prevents or treats a bioterrorism-related illness would receive a voucher for extended patent life for a different product. ${ }^{40}$ Whereas a patent extension delays entry of generics, the priority-review voucher speeds entry of generics, because it speeds the launch of the brand-name drug and likely moves its patent expiration forward.

Given its relatively low cost, the priority-review voucher could be part of a larger toolkit including both push and pull mechanisms. Whereas the voucher could motivate developers to continue with existing programs, awards such as the proposed $\$ 3$ billion APC could motivate entirely new programs. Furthermore, if the APC were directed at malaria, tuberculosis, and HIV/AIDS, then the voucher could be applied to other diseases.

The priority-review voucher could provide benefits in developing countries and the United States at relatively low cost. These two benefits are separable in theory, but we believe that they are more politically palatable when linked. The voucher would appeal to pharmaceutical manufacturers, consumers (who appreciate faster access to blockbuster drugs), the military (whose personnel operate in developing countries and might be exposed to neglected diseases), and advocates for health in developing countries. 
The authors are grateful for research support from the GlaxoWellcome Foundation and the Center for the Advancement for Social Entrepreneurship. They appreciate helpful comments from Clay Ackerly, Beth Anderson, Greg Dees, Adrian Gottschalk, Morna Miller, Kevin Schulman, Ripal Shah, Adrian Towse, referees, and participants at the 2005 meetings of the American Economic Association, International Health Economics Association, and Ad Hoc Working Group.

\section{NOTES}

1. Calculation using Table 3 of World Health Organization, World Health Report 2004: Changing History, 2004, http://www.who.int/whr/2004/en (accessed 21 December 2005).

2. D. Wirth, "A Harvest Not Yet Reaped: Genomics to New Drugs in Leishmania and Trypanosomes," DND Working Group Expert Paper, September 2001, http://www.dndi.org/pdf_files/harvest.pdf (accessed 21 December 2005).

3. R. MacDonald, "Prioritising Neglected Diseases Related to Poverty," British Medical Journal 331, no. 7507 (2005): 12.

4. WHO, World Health Report 2004.

5. The neglected diseases were identified independently by the International Federation of Pharmaceutical Manufacturers Association (http://wwwifpma.org) and by a Médecins sans Frontières (http://www .accessmed-msf.org/dnd/) working group. FDA approval is a conservative requirement, because the FDA might reject a vaccine that would not pass a risk-benefit test in the United States but would pass in a developing country. See M. Kremer, "Pharmaceuticals and the Developing World," Journal of Economic Perspectives 16, no. 4 (2002): 67-90. Some developers will not hold all patent rights, but the voucher creates a financial incentive for the patent holders to negotiate. John Walsh and colleagues found little empirical basis for claims that patent thickets impede biomedical research. J.P. Walsh, C. Cho, and W.M. Cohen, "View from the Bench: Patents and Material Transfers," Science 309, no. 5743 (2005): 2002-2003.

6. The voucher would grant the bearer the same treatment as other priority drugs, so review time would be six months, on average, but not guaranteed.

7. Pharmaceutical R\&D Policy Project, Wellcome Trust-LSE, "Fast Track Options as a Fundraising Mechanism to Support R\&D into Neglected Diseases," January 2005, http://www.lse.ac.uk/collections/ LSEHealthAndSocialCare/documents/PRPP/FastTrackOption(FTO\%20January2005.pdf (accessed 21 December 2005).

8. WHO, World Health Report 2004.

9. With little revenue at stake, most manufacturers forgo patent protection for essential drugs in developing countries. A. Attaran, "How Do Patents and Economic Policies Affect Access to Essential Medicines in Developing Countries?" Health Affairs 23, no. 3 (2004): 155-166.

10. The World Health Report 2004 (p. 157) classifies the following countries as developed: all countries in Europe (including Israel and Turkey), parts of North America (Canada, Cuba, and the United States), and parts of the western Pacific (Australia, Brunei, Japan, New Zealand, and Singapore).

11. See J.O. Lanjouw, "Opening Doors to Research: A New Global Patent Regime for Pharmaceuticals," Brookings Review 21, no. 2 (2003): 13-17.

12. H. Grabowski, "Encouraging the Development of New Vaccines," Health Affairs 24, no. 3 (2005): 697-700.

13. C. Milne, K. Kaitin, and E. Ronchi, "Orphan Drug Laws in Europe and the U.S.: Incentives for Research and Development of Medicines for Diseases of Poverty," Commission on Macroeconomics and Health Working Paper no. WG2: 9, http://www.cmhealth.org/docs/wg2_paper9.pdf (accessed 21 December 2005); and H. Kettler, "Narrowing the Gap between Provision and Need for Medicines in Developing Countries" (London: Office of Health Economics, 2000).

14. Kettler, "Narrowing the Gap."

15. V.G. Hale, K. Woo, and H.L. Lipton, "Oxymoron No More: The Potential of Nonprofit Drug Companies to Deliver on the Promise of Medicines for the Developing World," Health Affairs 24, no. 4 (2005): 1057-1063.

16. H.E. Kettler and S. Marjanovic, "Engaging Biotechnology Companies in the Development of Innovative Solutions for Diseases of Poverty," Nature Reviews: Drug Discovery 3, no. 2 (2004): 171-176.

17. "Foundation," Economist, 27 January 2005.

18. E.R. Berndt et al., "Advanced Purchase Commitments for a Malaria Vaccine: Estimating Costs and Effectiveness," NBER Working Paper no. 11288 (Cambridge, Mass.: National Bureau of Economic Research, 
May 2005); and E.R. Berndt and J.A. Hurvitz, "Vaccine Advance-Purchase Agreements for Low-Income Countries: Practical Issues," Health Affairs 24, no. 3 (2005): 653-665.

19. Kettler, "Narrowing the Gap."

20. Detailed calculations are provided in a technical appendix, available online at http://content.healthaffairs .org/cgi/content/full/25/2/313/DCl.

21. D. Dranove and D. Meltzer, "Do Important Drugs Reach the Market Sooner?" RAND Journal of Economics 25, no. 3 (1994): 402-423.

22. Adrian Gottschalk, associate director, Biogen, provided data on median review times under PDUFA-II See also E.R. Berndt et al., "Industry Funding of the FDA: Effects of PDUFA on Approval Times and Withdrawal Rates," Nature Reviews: Drug Discovery 4, no. 7 (2005): 545-554.

23. Moving the launch date forward by one year moves the patent expiration forward by one year for most drugs. Under the Hatch-Waxman Act, most drugs are eligible for compensatory increases in effective patent life equal to the time lost in regulatory review. H. Grabowski and J. Vernon, "Effective Patent Life in Pharmaceuticals," International Journal of Technology Management 19, nos. 1/2 (2000): 98-120.

24. D. Carpenter and A.M. Fendrick, "Accelerating Approval Times for New Drugs in the United States," Regulatory Affairs Journal-Pharma 15, no. 6 (2004): 411-417.

25. R. Katz, "How a Band of Technical Renegades Designed the Alpha Chip," Research Technology Management 36, no. 6 (1993): 13-20; and S. Stern, "Do Scientists Pay to Be Scientists?" Management Science 50, no. 6 (2004): 835-854.

26. J.A. DiMasi, R.W. Hansen, and H.G. Grabowski, "The Price of Innovation: New Estimates of Drug Development Costs," Journal of Health Economics 22, no. 2 (2003): 151-185. The out-of-pocket cost per new drug is $\$ 403$ million (2000 dollars), and capitalizing out-of-pocket costs to the point of marketing approval at a real discount rate of 11 percent yields a total preapproval cost of $\$ 802$ million.

27. Ibid.

28. M.S. Smolinski, M.A. Hamburg, and J. Lederberg, eds., Microbial Threats to Health: Emergence, Detection, and Response (Washington: National Academies Press, 2002), 184; WHO, "Genomics and World Health: Report of the Advisory Committee on Health Research," 25 November 2002, http://www.who.int/gb/ebwha/ pdf_files/EBlll/eebllll2.pdf (accessed 30 January 2006); and J.A. DiMasi, H.G. Grabowski, and J. Vernon, "R\&D Costs and Returns by Therapeutic Category," Drug Information Journal 38, no. 3 (2004): 211-223.

29. Kremer, "Pharmaceuticals and the Developing World."

30. P.J. Neumann et al., "Are Pharmaceuticals Cost-Effective? A Review of the Evidence," Health Affairs 19, no. 2 (2000): 92-109.

31. Consumer surplus is equal to half of producer surplus if the demand curve is linear and marginal costs are constant. This method of calculating consumer surplus applies when the manufacturer has market power. In the case of the drug for neglected diseases, we assume that the drug is available as a generic, so the price would be near marginal cost, and consumer surplus would be much greater.

32. C.M. Morel et al., "Health Innovation Networks to Help Developing Countries Address Neglected Diseases," Science 309, no. 5733 (2005): 401-404.

33. A. Towse and H. Kettler, "Advance Price or Purchase Commitments to Create Markets for Treatments for Diseases of Poverty: Lessons from Three Policies," Bulletin of the World Health Organization 83, no. 4 (2005): 301-307.

34. Kremer, "Pharmaceuticals and the Developing World."

35. K.J. Arrow, "New Antimalarial Drugs: Biology and Economics Meet," Finance and Development 41, no. 1 (2004): 20-2l.

36. Berndt et al., "Industry Funding of the FDA."

37. M.K. Olson, "Are Novel Drugs More Risky for Patients than Less Novel Drugs?" Journal of Health Economics 23, no. 6 (2004): 1135-1158.

38. Tufts Center for the Study of Drug Development, "Drug Safety Withdrawals in the U.S. Not Linked to Speed of FDA Approval," Tufts CSDD Impact Report 7, no. 5 (2005): 1-4.

39. D.B. Ridley et al., "Spending on Postapproval Drug Safety," Health Affairs 25, no. 2 (2006): 429-436.

40. S. Lueck, “'Bioshield' Drug-Patent Plan Draws Fire: Generics Makers Fight Extending Exclusivity Protection to Areas Outside Biodefense," Wall Street Journal, 1 April 2005. 